
fallecimientos ocurren en accidentes donde el vehículo choca con una determinada parte o el pasajero se encuentra en una posición concreta en el vehículo. Además, la situación se acrecienta en viajes hacia el trabajo o para llevar a los niños al colegio, con datos históricos que despuntan.

\section{El algoritmo}

Los resultados ofrecen mayor acierto en accidentes graves que leves, algo que para el investigador es preferible, ya que su objetivo es salvar vidas. "Con los métodos estadísticos de nuestro modelo podemos decir que en España la probabilidad media de que un accidente de coche sea leve es de un $97^{\prime} 44 \%$ y, por lo tanto, de un $2^{\prime} 56 \%$ de que sea grave 0 acabe en muerte".

Una de las características importantes es la influencia de la posición en el vehículo. Por ejemplo, en un autobús cuando una persona permanece de pie la probabilidad de fallecer aumenta considerablemente. Pero si, además, se suman características como la iluminación de la vía o el tipo de maniobra que está haciendo el vehículo la probabilidad de accidente puede aumentar o disminuir en términos absolutos. Es decir, lo que se consideraría acercarse al peor 0 al mejor accidente.

Los datos experimentales, basados en el histórico, determinaron que el peor accidente sería un impacto de una motocicleta, con la víctima conduciendo, de noche sin iluminación en la vía, a una edad de 70 años, cruzando una intersección, con la calzada seca, sin anomalías en la moto, en una curva suave y en una vía interurbana. En estas condiciones, el algoritmo determinó que la probabilidad de que sucediera un accidente grave o que la víctima falleciera es de un $98 \%$. El modelo, además, podría llegar a predecir qué pasaría si fueran dos personas en la motocicleta.

\section{Un caso real}

David Úbeda y sus colaboradores quisieron analizar qué pasaría con un accidente ocurrido en la actualidad. En concreto, los investigadores se fijaron en un tramo de la carretera de Burgos a la altura de Atapuerca. Unos 70 kilómetros de recorrido en una vía de doble sentido, nacional, en la que circula una autopista en paralelo, situada junto a una zona montañosa y en la que el $80 \%$

\section{David Úbeda espera que la DGT tome en consideración los datos obtenidos en la tesis}

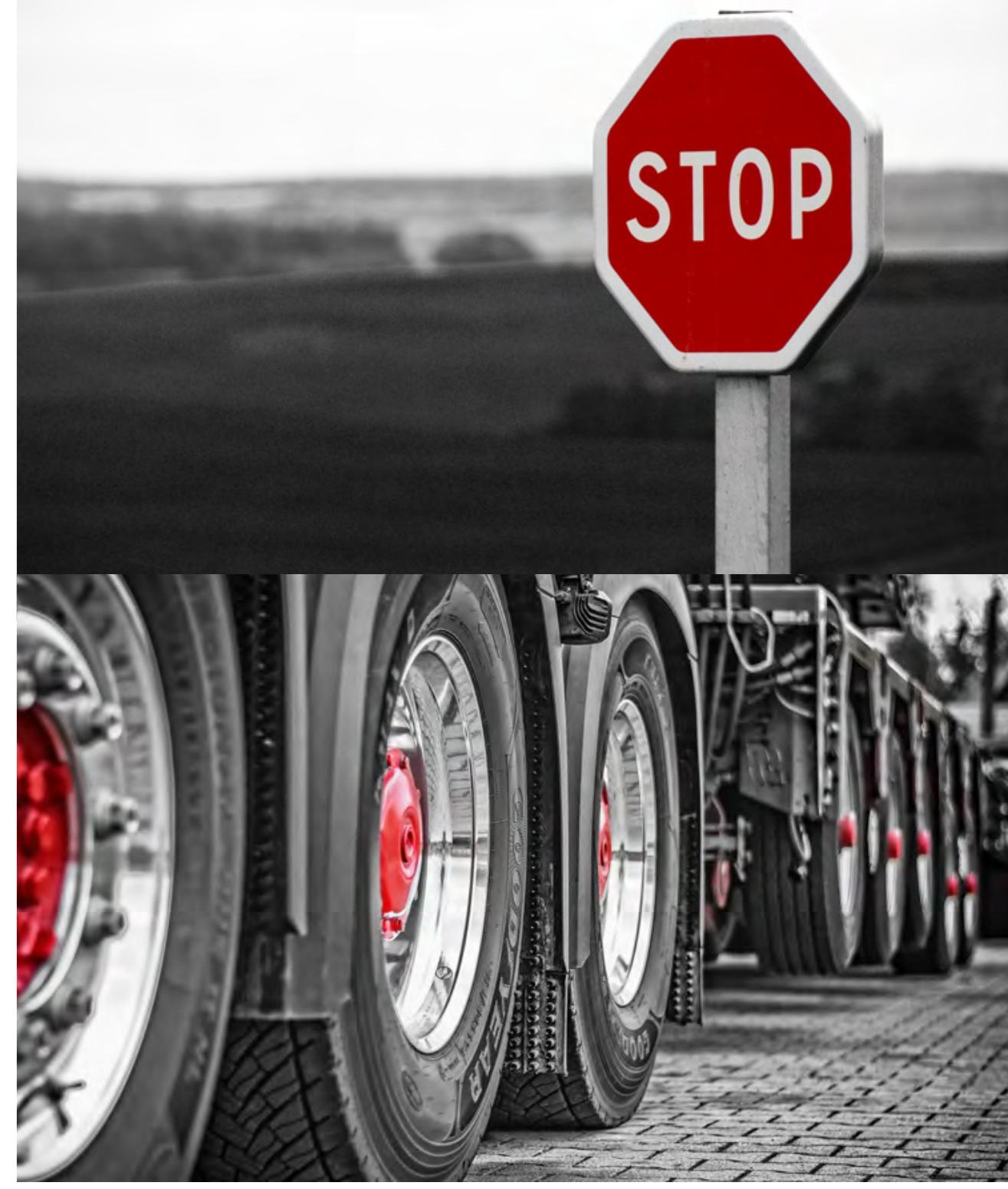

del tráfico que circula son vehículos de alto tonelaje. "En 14 años han fallecido 117 personas en esta carretera", señala el profesor de la UMH.

La razón por la que los camiones circulan por esta carretera es que la autopista cuesta 11 euros y, por tanto, los vehículos comerciales optan también por la nacional. Una de las claves para disminuir el número de accidentes en este tramo sería eliminar el peaje y que se pudiera circular de forma gratuita por la autopista, o bien que ciertos vehículos pesados pudieran hacerlo a coste cero. "En los pueblos de alrededor como, por ejemplo, Pancorbo, todos conocen un caso de persona fallecida en esa vía", cuenta David Úbeda. "Incluso existe una plataforma de afectados", subraya.

Los datos económicos del Ministerio de Fomento indican que liberar la vía tendría un único coste de unos 125 millones de euros. El investigador recuerda que, si en 10 años han fallecido 117 personas, el coste es mucho más elevado en el futuro. Por su parte, la DGT afirma que los accidentes ocurridos en la carretera de Pancorbo no se producen por la peligrosidad de la vía, sino porque los conductores se distraen en estos tramos. El profesor de la UMH subraya que una distracción en ciudad, por ejemplo, para aumentar o disminuir el volumen de la radio puede permitir una maniobra de rectificación. "El problema es que, en este tramo, si te distraes, mueres, porque no hay posibilidad de rectificar", aclara. Tal y como recoge la tesis doctoral, las particularidades de la vía son determinantes a la hora de clasificar su peligrosidad y la gravedad de los accidentes.

David Úbeda asegura que mediante la publicación de esta Tesis Doctoral esperan que la DGT tomen en consideración esta investigación, pero, de momento, no se va a atender de forma prioritaria. Según explica, se les emplaza a participar en convocatorias de proyectos de innovación. Pero, en opinión del doctorando, es fundamental dar prioridad a los avances científicos en este sentido, de manera que exista una colaboración entre ambas entidades. Es decir, una transferencia del conocimiento generado en la universidad a la sociedad.

Ante la llegada inminente del vehículo autónomo, el profesor de la UMH cree que hay que buscar soluciones diferentes, como el uso de algoritmos: "En el futuro, conducirá la CPU de un ordenador, por lo que cobra más sentido que nunca que seamos capaces de predecir y decidir qué hacer en función de los datos matemáticos". 